\title{
Fixed point theorems for generalized contractive type multivalued maps
}

\author{
Buthinah A Bin Dehaish ${ }^{1 *}$ and Abdul Latif ${ }^{2}$
}

${ }^{*}$ Correspondence:

bbindehaish@yahoo.com

'Department of Mathematics

Faculty of Science For Girls, King

Abdulaziz University, P.O. Box 53909,

Jeddah, 21593, Saudi Arabia

Full list of author information is

available at the end of the article

\begin{abstract}
Without using the concept of Hausdorff metric, we prove some results on the existence of fixed points for generalized contractive multivalued maps with respect to u-distance. Consequently, several known fixed point results are either generalized or improved.
\end{abstract}

MSC: $47 \mathrm{H} 10 ; 54 \mathrm{H} 25$

Keywords: metric space; $u$-distance; contractive map; fixed point

\section{Introduction}

Using the concept of Hausdorff metric, Nadler [11] introduced the notion of multivalued contraction maps and proved a multivalued version of the well-known Banach contraction principle, which states that each closed bounded valued contraction map on a complete metric space has a fixed point. Since then various fixed point results concerning multivalued contractions have appeared.

Without using the concept of Hausdorff metric, most recently Feng and Liu [4] extended Nadler's fixed point result, while Klim and Wardowski [7] generalized their corresponding fixed point result in [4].

In [6] Kada et al. introduced the notion of $w$-distance and improved several classical results including Caristi's fixed point theorem. Suzuki and Takahashi [12] introduced singlevalued and multivalued weakly contractive maps with respect to $w$-distance and proved fixed point results for such maps. Consequently, they generalized the Banach contraction principle and Nadler's fixed point result. Generalizing the concept of $w$-distance, Suzuki [13] introduced the notion of $\tau$-distance on a metric space and improved several classical results including the corresponding results of Suzuki and Takahashi [12]. In literature, several other kinds of distances and various versions of known results have appeared. For example, see $[1-3,10]$ and references therein. Most recently, Ume [14] generalized the notion of $\tau$-distance by introducing the concept of $u$-distance.

In this paper, first we prove our key lemma for multivalued general contractive maps with respect to $u$-distance and then prove some results on the existence of fixed points for such multivalued maps. Consequently, several known fixed point results get either improved or generalized including the corresponding results of Feng and Liu [4], Klim and Wardowski [7], Latif and Albar [9], Suzuki and Takahashi [12], Latif and Abdou [8], and Nadler [11].

Let $(X, d)$ be a metric space. We denote the collection of nonempty subsets of $X$, nonempty closed subsets of $X$ and nonempty closed bounded subsets of $X$ by $2^{X}, C l(X)$

\section{Springer}

(C) 2012 Bin Dehaish and Latif; licensee Springer. This is an Open Access article distributed under the terms of the Creative Commons Attribution License (http://creativecommons.org/licenses/by/2.0), which permits unrestricted use, distribution, and reproduction in any medium, provided the original work is properly cited. 
and $C B(X)$ respectively. Let $H$ be the Hausdorff metric with respect to $d$, that is,

$$
H(A, B)=\max \left\{\sup _{x \in A} d(x, B), \sup _{y \in B} d(y, A)\right\},
$$

for every $A, B \in C B(X)$, where $d(x, B)=\inf _{y \in B} d(x, y)$.

A point $x \in X$ is called a fixed point of $T: X \rightarrow 2^{X}$ if $x \in T(x)$. We denote $\operatorname{Fix}(T)=\{x \in$ $X: x \in T(x)\}$.

A sequence $\left\{x_{n}\right\}$ in $X$ is called an orbit of $T$ at $x_{0} \in X$ if $x_{n} \in T\left(x_{n-1}\right)$ for all $n \geq 1$. A map $\phi: X \rightarrow \mathbb{R}$ is called $T$-orbitally lower semicontinuous if, for any orbit $\left\{x_{n}\right\}$ of $T$ and $x \in X$, $x_{n} \rightarrow x$ imply that $\phi(x) \leq \liminf _{n \rightarrow \infty} \phi\left(x_{n}\right)$.

Most recently, Ume [14] generalized the notion of $\tau$-distance by introducing $u$-distance as follows.

A function $p: X \times X \rightarrow \mathbb{R}_{+}$is called a $u$-distance on $X$ if there exists a function $\theta$ : $X \times X \times \mathbb{R}_{+} \times \mathbb{R}_{+} \rightarrow \mathbb{R}_{+}$such that the following hold for $x, y, z \in X:$

$\left(u_{1}\right) p(x, z) \leq p(x, y)+p(y, z)$

$\left(u_{2}\right) \theta(x, y, 0,0)=0$ and $\theta(x, y, s, t) \geq \min \{s, t\}$ for each $s, t \in \mathbb{R}_{+}$, and for every $\epsilon>0$, there exists $\delta>0$ such that $\left|s-s_{0}\right|<\delta,\left|t-t_{0}\right|<\delta, s, s_{0}, t, t_{0} \in R_{+}$and $y \in X$ imply

$$
\left|\theta(x, y, s, t)-\theta\left(x, y, s_{0}, t_{0}\right)\right|<\epsilon
$$

$\left(u_{3}\right)$

$$
\begin{aligned}
& \lim _{n \rightarrow \infty} x_{n}=x, \\
& \lim _{n \rightarrow \infty} \sup \left\{\theta\left(w_{n}, z_{n}, p\left(w_{n}, x_{m}\right), p\left(z_{n}, x_{m}\right)\right): m \geq n\right\}=0
\end{aligned}
$$

imply

$$
p(y, x) \leq \liminf _{n \rightarrow \infty} p\left(y, x_{n}\right)
$$

$\left(u_{4}\right)$

$$
\begin{aligned}
& \lim _{n \rightarrow \infty} \sup \left\{p\left(x_{n}, w_{m}\right): m \geq n\right\}=0, \\
& \lim _{n \rightarrow \infty} \sup \left\{p\left(y_{n}, z_{m}\right): m \geq n\right\}=0, \\
& \lim _{n \rightarrow \infty} \theta\left(x_{n}, w_{n}, s_{n}, t_{n}\right)=0, \\
& \lim _{n \rightarrow \infty} \theta\left(y_{n}, z_{n}, s_{n}, t_{n}\right)=0
\end{aligned}
$$

imply

$$
\lim _{n \rightarrow \infty} \theta\left(w_{n}, z_{n}, s_{n}, t_{n}\right)=0
$$


or

$$
\begin{aligned}
& \lim _{n \rightarrow \infty} \sup \left\{p\left(w_{n}, x_{m}\right): m \geq n\right\}=0, \\
& \lim _{n \rightarrow \infty} \sup \left\{p\left(z_{m}, y_{n}\right): m \geq n\right\}=0, \\
& \lim _{n \rightarrow \infty} \theta\left(x_{n}, w_{n}, s_{n}, t_{n}\right)=0, \\
& \lim _{n \rightarrow \infty} \theta\left(y_{n}, z_{n}, s_{n}, t_{n}\right)=0
\end{aligned}
$$

imply

$$
\lim _{n \rightarrow \infty} \theta\left(w_{n}, z_{n}, s_{n}, t_{n}\right)=0
$$

$\left(u_{5}\right)$

$$
\begin{aligned}
& \lim _{n \rightarrow \infty} \theta\left(w_{n}, z_{n}, p\left(w_{n}, x_{n}\right), p\left(z_{n}, x_{n}\right)\right)=0, \\
& \lim _{n \rightarrow \infty} \theta\left(w_{n}, z_{n}, p\left(w_{n}, y_{n}\right), p\left(z_{n}, y_{n}\right)\right)=0
\end{aligned}
$$

imply

$$
\lim _{n \rightarrow \infty} d\left(x_{n}, y_{n}\right)=0
$$

or

$$
\begin{aligned}
& \lim _{n \rightarrow \infty} \theta\left(a_{n}, b_{n}, p\left(x_{n}, a_{n}\right), p\left(x_{n}, b_{n}\right)\right)=0, \\
& \lim _{n \rightarrow \infty} \theta\left(a_{n}, b_{n}, p\left(y_{n}, a_{n}\right), p\left(y_{n}, b_{n}\right)\right)=0
\end{aligned}
$$

imply

$$
\lim _{n \rightarrow \infty} d\left(x_{n}, y_{n}\right)=0
$$

\section{Remark 1.1 [14]}

(a) Suppose that $\theta$ from $X \times X \times \mathbb{R}_{+} \times \mathbb{R}_{+}$into $\mathbb{R}_{+}$is a mapping satisfying $\left(u_{2}\right) \backsim\left(u_{5}\right)$. Then there exists a mapping $\eta$ from $X \times X \times \mathbb{R}_{+} \times \mathbb{R}_{+}$into $\mathbb{R}_{+}$such that $\eta$ is nondecreasing in its third and fourth variable respectively, satisfying $\left(u_{2}\right) \eta \backsim\left(u_{5}\right) \eta$, where $\left(u_{2}\right) \eta \backsim\left(u_{5}\right) \eta$ stand for substituting $\eta$ for $\theta$ in $\left(u_{2}\right) \backsim\left(u_{5}\right)$ respectively.

(b) In the light of (a), we may assume that $\theta$ is nondecreasing in its third and fourth variables, respectively, for a function $\theta$ from $X \times X \times \mathbb{R}_{+} \times \mathbb{R}_{+}$into $\mathbb{R}_{+}$satisfying $\left(u_{2}\right) \backsim\left(u_{5}\right)$.

(c) Each $\tau$-distance $p$ on a metric space $(X, d)$ is also a $u$-distance on $X$.

We present some examples of $u$-distances which are not $\tau$-distances. For details, see [14].

Example 1.2 Let $X=\mathbb{R}_{+}$with the usual metric. Define $p: X \times X \rightarrow \mathbb{R}_{+}$by $p(x, y)=\left(\frac{1}{4}\right) x^{2}$. Then $p$ is a $u$-distance on $X$ but not a $\tau$-distance on $X$. 
Example 1.3 Let $X$ be a normed space with norm $\|\cdot\|$. Then a function $p: X \times X \rightarrow \mathbb{R}_{+}$ defined by $p(x, y)=\|x\|$ for every $x, y \in X$ is a $u$-distance on $X$ but not a $\tau$-distance.

It follows from the above examples and Remark 1.1(c) that $u$-distance is a proper extension of $\tau$-distance. Other useful examples on $u$-distance are also given in [14].

Let $(X, d)$ be a metric space and let $p$ be a $u$-distance on $X$. A sequence $\left\{x_{n}\right\}$ in $X$ is called $p$-Cauchy [14] if there exists a function $\theta$ from $X \times X \times \mathbb{R}_{+} \times \mathbb{R}_{+}$into $\mathbb{R}_{+}$satisfying $\left(u_{2}\right) \backsim\left(u_{5}\right)$ and a sequence $\left\{z_{n}\right\}$ of $X$ such that

$$
\lim _{n \rightarrow \infty} \sup \left\{\theta\left(z_{n}, z_{n}, p\left(z_{n}, x_{m}\right), p\left(z_{n}, x_{m}\right)\right): m \geq n\right\}=0,
$$

or

$$
\lim _{n \rightarrow \infty} \sup \left\{\theta\left(z_{n}, z_{n}, p\left(x_{m}, z_{n}\right), p\left(x_{m}, z_{n}\right)\right): m \geq n\right\}=0 .
$$

The following lemmas concerning $u$-distance are crucial for our results.

Lemma 1.4 [14] Let $(X, d)$ be a metric space and let $p$ be a u-distance on $X$. If $\left\{x_{n}\right\}$ is a $p$-Cauchy sequence in $X$, then $\left\{x_{n}\right\}$ is a Cauchy sequence.

Lemma 1.5 [5] Let $(X, d)$ be a metric space and let $p$ be a $u$-distance on $X$. If $\left\{x_{n}\right\}$ is a $p$-Cauchy sequence and $\left\{y_{n}\right\}$ is a sequence satisfying

$$
\lim _{n \rightarrow \infty} \sup \left\{p\left(x_{n}, y_{m}\right): m \geq n\right\}=0
$$

then $\left\{y_{n}\right\}$ is also a $p$-Cauchy sequence and $d\left(x_{n}, y_{n}\right)=0$.

Lemma 1.6 [14] Let $(X, d)$ be a metric space and let $p$ be a u-distance on $X$. Suppose that a sequence $\left\{x_{n}\right\}$ of $X$ satisfies

$$
\lim _{n \rightarrow \infty} \sup \left\{p\left(x_{n}, x_{m}\right): m>n\right\}=0,
$$

or

$$
\lim _{n \rightarrow \infty} \sup \left\{p\left(x_{m}, x_{n}\right): m>n\right\}=0 .
$$

Then $\left\{x_{n}\right\}$ is a p-Cauchy sequence.

We say that a multivalued map $T: X \rightarrow 2^{X}$ is generalized $p$-contractive if there exist a $u$-distance $p$ on $X$ and a constant $b \in(0,1)$ such that, for any $x \in X$, there is $y \in J_{b}^{x}$ satisfying

$$
p(y, T(y)) \leq k(p(x, y)) p(x, y)
$$

where $J_{b}^{x}=\{y \in T(x): b p(x, y) \leq p(x, T(x))\}$ and $k$ is a function from $[0, \infty)$ to $[0, b)$ with $\lim \sup _{r \rightarrow t^{+}} k(r)<b$ for each $t \in[0, \infty)$.

Note that if we take $u=d$, then the definition of a generalized $p$-contractive map reduces to the definition of a generalized contractive map due to Klim and Wardowski [7]. 
In particular, if we take $u=d$ and a constant map $k=h<b, h \in(0,1)$, then the generalized $p$-contractive map $T$ reduces to the definition of contractive maps due to Feng and Liu [4].

\section{The results}

First, we prove our key lemma in the setting of metric spaces.

Lemma 2.1 Let $(X, d)$ be a metric space. Let $T: X \rightarrow C l(X)$ be a generalized $p$-contractive map. Then, there exists an orbit $\left\{u_{n}\right\}$ of $T$ at $u_{0} \in X$ such that the sequence of nonnegative real numbers $\left\{p\left(u_{n}, T\left(u_{n}\right)\right)\right\}$ is decreasing to zero and $\left\{u_{n}\right\}$ is a Cauchy sequence.

Proof Since $T(x) \in C l(X)$ for any $x \in X, J_{b}^{x}$ is nonempty for any constant $b \in(0,1)$. Let $u_{0}$ be an arbitrary but fixed element of $X$, there exists $u_{1} \in J_{b}^{u_{0}} \subseteq T\left(u_{0}\right)$ such that

$$
\begin{aligned}
& p\left(u_{1}, T\left(u_{1}\right)\right) \leq k\left(p\left(u_{0}, u_{1}\right)\right) p\left(u_{0}, u_{1}\right), \quad k\left(p\left(u_{0}, u_{1}\right)\right)<b, \\
& b p\left(u_{0}, u_{1}\right) \leq p\left(u_{0}, T\left(u_{0}\right)\right) .
\end{aligned}
$$

Using (16) and (17), we have

$$
\begin{aligned}
p\left(u_{0}, T\left(u_{0}\right)\right)-p\left(u_{1}, T\left(u_{1}\right)\right) & \geq b p\left(u_{0}, u_{1}\right)-k\left(p\left(u_{0}, u_{1}\right)\right) p\left(u_{0}, u_{1}\right) \\
& =\left[b-k\left(p\left(u_{0}, u_{1}\right)\right)\right] p\left(u_{0}, u_{1}\right)>0 .
\end{aligned}
$$

Similarly, there is $u_{2} \in J_{b}^{u_{1}} \subseteq T\left(u_{1}\right)$ such that

$$
\begin{aligned}
& p\left(u_{2}, T\left(u_{2}\right)\right) \leq k\left(p\left(u_{1}, u_{2}\right)\right) p\left(u_{1}, u_{2}\right), \quad k\left(p\left(u_{1}, u_{2}\right)\right)<b, \\
& b p\left(u_{1}, u_{2}\right) \leq p\left(u_{1}, T\left(u_{1}\right)\right) .
\end{aligned}
$$

Using (19) and (20), we have

$$
\begin{aligned}
p\left(u_{1}, T\left(u_{1}\right)\right)-p\left(u_{2}, T\left(u_{2}\right)\right) & \geq b p\left(u_{1}, u_{2}\right)-k\left(p\left(u_{1}, u_{2}\right)\right) p\left(u_{1}, u_{2}\right) \\
& =\left[b-k\left(p\left(u_{1}, u_{2}\right)\right)\right] p\left(u_{1}, u_{2}\right)>0 .
\end{aligned}
$$

From (16) and (20), it follows that

$$
p\left(u_{1}, u_{2}\right) \leq \frac{1}{b} p\left(u_{1}, T\left(u_{1}\right)\right) \leq \frac{1}{b} k\left(p\left(u_{0}, u_{1}\right)\right) p\left(u_{0}, u_{1}\right) \leq p\left(u_{0}, u_{1}\right) .
$$

Continuing this process, we get an orbit $\left\{u_{n}\right\}$ of $T$ in $X$ such that $u_{n+1} \in J_{b}^{u_{n}} \subseteq T\left(u_{n}\right)$,

$$
\begin{aligned}
& b p\left(u_{n}, u_{n+1}\right) \leq p\left(u_{n}, T\left(u_{n}\right)\right), \\
& p\left(u_{n+1}, T\left(u_{n+1}\right)\right) \leq k\left(p\left(u_{n}, u_{n+1}\right)\right) p\left(u_{n}, u_{n+1}\right), \quad k\left(p\left(u_{n}, u_{n+1}\right)\right)<b .
\end{aligned}
$$

Using (23) and (24), we get

$$
\begin{aligned}
p\left(u_{n}, T\left(u_{n}\right)\right)-p\left(u_{n+1}, T\left(u_{n+1}\right)\right) & \geq b p\left(u_{n}, u_{n+1}\right)-k\left(p\left(u_{n}, u_{n+1}\right)\right) p\left(u_{n}, u_{n+1}\right) \\
& =\left[b-k\left(p\left(u_{n}, u_{n+1}\right)\right)\right] p\left(u_{n}, u_{n+1}\right)>0,
\end{aligned}
$$


and thus for each $n$

$$
\begin{aligned}
& p\left(u_{n}, T\left(u_{n}\right)\right)>p\left(u_{n+1}, T\left(u_{n+1}\right)\right), \\
& p\left(u_{n}, u_{n+1}\right) \leq p\left(u_{n-1}, u_{n}\right) .
\end{aligned}
$$

Note that the sequences $\left\{p\left(u_{n}, T\left(u_{n}\right)\right)\right\}$ and $\left\{p\left(u_{n}, u_{n+1}\right)\right\}$ are decreasing and bounded, thus convergent. Now, by definition of the function $k$ there exists $\alpha \in[0, b)$ such that

$$
\limsup _{n \rightarrow \infty} k\left(p\left(u_{n}, u_{n+1}\right)\right)=\alpha
$$

Thus for any $b_{0} \in(\alpha, b)$, there exists $n_{0} \in \mathbb{N}$ such that for each $n>n_{0}$

$$
k\left(p\left(u_{n}, u_{n+1}\right)\right)<b_{0}
$$

and thus for each $n>n_{0}$, we have

$$
k\left(p\left(u_{n}, u_{n+1}\right)\right) \times \cdots \times k\left(p\left(u_{n_{0}+1}, u_{n_{0}+2}\right)\right)<b_{0}^{n-n_{0}} .
$$

Also, it follows from (25) that for each $n>n_{0}$,

$$
p\left(u_{n}, T\left(u_{n}\right)\right)-p\left(u_{n+1}, T\left(u_{n+1}\right)\right) \geq \beta p\left(u_{n}, u_{n+1}\right),
$$

where $\beta=b-b_{0}$. Using (23) and (24), for each $n>n_{0}$, we have

$$
\begin{aligned}
p\left(u_{n+1}, T\left(u_{n+1}\right)\right) \leq & k\left(p\left(u_{n}, u_{n+1}\right)\right) p\left(u_{n}, u_{n+1}\right) \\
\leq & \frac{1}{b} k\left(p\left(u_{n}, u_{n+1}\right)\right) p\left(u_{n}, T\left(u_{n}\right)\right) \\
\leq & \frac{1}{b^{2}} k\left(p\left(u_{n}, u_{n+1}\right)\right) k\left(p\left(u_{n-1}, u_{n}\right)\right) p\left(u_{n-1}, T\left(u_{n-1}\right)\right) \\
& \vdots \\
\leq & \frac{1}{b^{n}}\left[k\left(p\left(u_{n}, u_{n+1}\right)\right) \times \cdots \times k\left(p\left(u_{1}, u_{2}\right)\right)\right] p\left(u_{1}, T\left(u_{1}\right)\right) \\
= & \frac{k\left(p\left(u_{n}, u_{n+1}\right)\right) \times \cdots \times k\left(p\left(u_{n_{0}+1}, u_{n_{0}+2}\right)\right)}{b^{n-n_{0}}} \\
& \times \frac{k\left(p\left(u_{n_{0}}, u_{n_{0}+1}\right)\right) \times \cdots \times k\left(p\left(u_{1}, u_{2}\right)\right) p\left(u_{1}, T\left(u_{1}\right)\right)}{b^{n_{0}}},
\end{aligned}
$$

and thus

$$
p\left(u_{n+1}, T\left(u_{n+1}\right)\right)<\left(\frac{b_{0}}{b}\right)^{n-n_{0}} \frac{k\left(p\left(u_{n_{0}}, u_{n_{0}+1}\right)\right) \times \cdots \times k\left(p\left(u_{1}, u_{2}\right)\right) p\left(u_{1}, T\left(u_{1}\right)\right)}{b^{n_{0}}} .
$$

Now, since $b_{0}<b$, we have $\lim _{n \rightarrow \infty}\left(\frac{b_{0}}{b}\right)^{n-n_{0}}=0$, and hence the decreasing sequence $\left\{p\left(u_{n}, T\left(u_{n}\right)\right)\right\}$ converges to 0 . Now, we show that $\left\{u_{n}\right\}$ is a Cauchy sequence. Note that for each $n>n_{0}$

$$
p\left(u_{n}, u_{n+1}\right) \leq \gamma^{n} p\left(u_{0}, u_{1}\right), \quad n=0,1,2, \ldots
$$


where $\gamma=\frac{b_{0}}{b}<1$. Thus, for any $n, m \in \mathbb{N}, m \geq n>n_{0}$, we get

$$
\begin{aligned}
p\left(u_{n}, u_{m}\right) & \leq \sum_{j=n}^{m-1} p\left(u_{j}, u_{j+1}\right) \\
& \leq\left(\gamma^{n}+\gamma^{n+1}+\cdots+\gamma^{m-1}\right) p\left(u_{0}, u_{1}\right) \\
& \leq \frac{\gamma^{n}}{1-\gamma} p\left(u_{0}, u_{1}\right)
\end{aligned}
$$

and hence

$$
\lim _{n \rightarrow \infty} \sup \left\{p\left(u_{n}, u_{m}\right): m \geq n\right\}=0
$$

Thus, by Lemma $1.6,\left\{u_{n}\right\}$ is a $p$-Cauchy sequence, and hence by Lemma $1.4,\left\{u_{n}\right\}$ is a Cauchy sequence.

Applying Lemma 2.1, we obtain the following main fixed point result.

Theorem 2.2 Let $(X, d)$ be a complete metric space and let $T: X \rightarrow C l(X)$ be a generalized $p$-contractive map. Suppose that a real valued function $f$ on $X$ defined by $f(u)=p(u, T(u))$ is T-orbitally lower semicontinuous. Then there exists $v_{0} \in X$ such that $v_{0} \in \operatorname{Fix}(T)$ and $p\left(v_{0}, v_{0}\right)=0$.

Proof By Lemma 2.1, there exists a Cauchy sequence $\left\{u_{n}\right\}$ in $X$ such that the decreasing sequence $\left\{f\left(u_{n}\right)\right\}=\left\{p\left(u_{n}, T\left(u_{n}\right)\right)\right\}$ converges to 0 . Due to the completeness of $X$, there exists some $v_{0} \in X$ such that $\lim _{n \rightarrow \infty} u_{n}=v_{0}$. Since $f$ is $T$-orbitally lower semicontinuous, we have

$$
0 \leq f\left(v_{0}\right) \leq \liminf _{n \rightarrow \infty} f\left(u_{n}\right)=0,
$$

that is, $f\left(v_{0}\right)=p\left(v_{0}, T\left(v_{0}\right)\right)=0$. Thus there exists a sequence $\left\{v_{n}\right\} \subset T\left(v_{0}\right)$ such that $\lim _{n \rightarrow \infty} p\left(v_{0}, v_{n}\right)=0$. It follows that

$$
0 \leq \lim _{n \rightarrow \infty} \sup \left\{p\left(u_{n}, v_{m}\right): m \geq n\right\} \leq \lim _{n \rightarrow \infty} \sup \left\{p\left(u_{n}, v_{0}\right)+p\left(v_{0}, v_{m}\right): m \geq n\right\}=0
$$

Since $\left\{u_{n}\right\}$ is a $p$-Cauchy sequence, it follows from (36) and Lemma 1.5 that $\left\{v_{n}\right\}$ is also a $p$-Cauchy sequence and $\lim _{n \rightarrow \infty} d\left(u_{n}, v_{n}\right)=0$. Thus, by Lemma $1.4,\left\{v_{n}\right\}$ is a Cauchy sequence in the complete space. Due to the closedness of $T\left(v_{0}\right)$, there exists $z_{0} \in X$ such that $\lim _{n \rightarrow \infty} v_{n}=z_{0} \in T\left(v_{0}\right)$. Consequently, using $\left(u_{3}\right)$ we get

$$
p\left(v_{0}, z_{0}\right) \leq \liminf _{n \rightarrow \infty} p\left(v_{0}, v_{n}\right) \leq 0,
$$

and thus $p\left(v_{0}, z_{0}\right)=0$. But, since $\lim _{n \rightarrow \infty} u_{n}=v_{0}, \lim _{n \rightarrow \infty} v_{n}=z_{0}$ and $\lim _{n \rightarrow \infty} d\left(u_{n}, v_{n}\right)=0$, we have $v_{0}=z_{0}$. Hence $v_{0} \in \operatorname{Fix}(T)$ and $p\left(v_{0}, v_{0}\right)=0$.

As a consequence of Theorem 2.2, we obtain the following fixed point result of Klim and Wardowski [7, Theorem 2.1] which contains the fixed point result of Feng and Liu [4, Theorem 3.1] and Nadler's fixed point theorem. 
Corollary 2.3 Let $(X, d)$ be a complete metric space and let $T: X \rightarrow C l(X)$ be a multivalued map such that a real-valued function $f$ on $X$ defined by $f(x)=d(x, T(x))$ is lower semi-continuous. If there exists $b \in(0,1)$ such that for any $x \in X$ there is $y \in I_{b}^{x}$ satisfying

$$
d(y, T(y)) \leq k(d(x, y)) d(x, y)
$$

where $I_{b}^{x}=\{y \in T(x): b d(x, y) \leq d(x, T(x))\}$; and $k$ is a function from $[0, \infty)$ to $[0, b)$ with $\lim \sup _{r \rightarrow t^{+}} k(r)<b$, for every $t \in[0, \infty)$. Then $\operatorname{Fix}(T) \neq \emptyset$.

\section{Remarks 2.4}

(a) Theorem 2.2 also generalizes fixed point theorems of Latif and Abdou [8, Theorem 2.2], Suzuki [13, Theorem 2], Suzuki and Takahashi [12, Theorem 1].

(b) It is worth mentioning that in the proofs of [7, Theorem 2.1], [4, Theorem 3.1], and [8, Theorem 2.2] a full force of the lower semicontinuity of the real-valued function $f$ is not used, but in fact $T$-orbitally lower semicontinuity of $f$ is enough to obtain the conclusions.

Applying Lemma 2.1, we also obtain the following fixed point result for a multivalued generalized $p$-contractive map where we use another suitable condition.

Theorem 2.5 Let $X$ be a complete metric space with metric $d$ and let $T: X \rightarrow C l(X)$ be a generalized $p$-contractive map. Assume that

$$
\inf \{p(u, v)+p(u, T(u)): u \in X\}>0,
$$

for every $v \in X$ with $v \notin T(v)$. Then $\operatorname{Fix}(T) \neq \phi$.

Proof By Lemma 2.1, there exists an orbit $\left\{u_{n}\right\}$ of $T$ which is a Cauchy sequence in a complete metric space $X$, so there exists some $v_{0} \in X$ such that $\lim _{n \rightarrow \infty} u_{n}=v_{0}$. Thus, using $\left(u_{3}\right)$ and (34), we have

$$
p\left(u_{n}, v_{0}\right) \leq \liminf _{m \rightarrow \infty} p\left(u_{n}, u_{m}\right) \leq \frac{\gamma^{n}}{1-\gamma} p\left(u_{0}, u_{1}\right),
$$

where $\gamma=\frac{b_{0}}{b}<1$. Also, we get

$$
p\left(u_{n}, T\left(u_{n}\right)\right) \leq p\left(u_{n}, u_{n+1}\right) \leq \gamma^{n} p\left(u_{0}, u_{1}\right) .
$$

Assume that $v_{0} \notin T\left(v_{0}\right)$. Then we have

$$
\begin{aligned}
0 & <\inf \left\{p\left(u, v_{0}\right)+p(u, T(u)): u \in X\right\} \\
& \leq \inf \left\{p\left(u_{n}, v_{0}\right)+p\left(u_{n}, T\left(u_{n}\right)\right): n>n_{0}\right\} \\
& \leq \inf \left\{\frac{\gamma^{n}}{1-\gamma} p\left(u_{0}, u_{1}\right)+\gamma^{n} p\left(u_{0}, u_{1}\right): n>n_{0}\right\} \\
& =\left\{\frac{2-\gamma}{1-\gamma} p\left(u_{0}, u_{1}\right)\right\} \inf \left\{\gamma^{n}: n>n_{0}\right\}=0,
\end{aligned}
$$

which is impossible, and hence $v_{0} \in \operatorname{Fix}(T)$. 
Remarks 2.6 Theorem 2.5 generalizes [8, Theorem 2.4] and [9, Theorem 3.3].

\section{Competing interests}

The authors declare that they have no competing interests.

Authors' contributions

Both authors contributed equally. The authors read and approved the final manuscript.

\section{Acknowledgements}

The authors thank the referees for their valuable comments. This paper was funded by the Deanship of Scientific Research (DSR), King Abdulaziz University, Jeddah, under Grant No.9-843-D1432. The authors, therefore, acknowledge with thanks technical and financial support of DSR.

\section{Author details}

'Department of Mathematics Faculty of Science For Girls, King Abdulaziz University, P.O. Box 53909, Jeddah, 21593, Saudi Arabia. ${ }^{2}$ Department of Mathematics Faculty of Science, King Abdulaziz University, P.O. Box 80203, Jeddah, 21589, Saudi Arabia.

Received: 6 April 2012 Accepted: 6 August 2012 Published: 31 August 2012

\section{References}

1. Al-Homidan, S, Ansari, QH, Yao, J-C: Some generalizations of Ekeland-type variational principle with applications to equilibrium problems and fixed point theory. Nonlinear Anal. 69, 126-139 (2008)

2. Ansari, QH: Vectorial form of Ekeland-type variational principle with applications to vector equilibrium problems and fixed point theory. J. Math. Anal. Appl. 334, 561-575 (2007)

3. Ansari, QH (ed.): Topics in Nonlinear Analysis and Optimization. World Education, Delhi (2012)

4. Feng, Y, Liu, S: Fixed point theorems for multivalued contractive mappings and multivalued Caristi type mappings. J. Math. Anal. Appl. 317, 103-112 (2006)

5. Hirunworkakit, S, Petrot, N: Some fixed point theorem for contractive multi-valued mappings induced by generalized distance in metric spaces. Fixed Point Theory Appl. 2011, 78 (2011). doi:10.116/1687-1812-2011-78

6. Kada, O, Susuki, T, Takahashi, W: Nonconvex minimization theorems and fixed point theorems in complete metric spaces. Math. Jpn. 44, 381-391 (1996)

7. Klim, D, Wardowski, D: Fixed point theorems for set-valued contractions in complete metric spaces. J. Math. Anal. Appl. 334, 132-139 (2007)

8. Latif, A, Abdou, AAN: Fixed points of generalized contractive maps. Fixed Point Theory Appl. 2009, Article ID 487161 (2009)

9. Latif, A, Albar, WA: Fixed point results in complete metric spaces. Demonstr. Math. 41, 145-150 (2008)

10. Lin, L-J, Wang, S-Y, Ansari, QH: Critical point theorems and Ekeland type variational principle with applications. Fixed Point Theory Appl. 2011, Article ID 914624 (2011)

11. Nadler, SB: Multivalued contraction mappings. Pac. J. Math. 30, 475-488 (1969)

12. Suzuki, T, Takahashi, W: Fixed point theorems and characterizations of metric completeness. Topol. Methods Nonlinear Anal. 8, 371-382 (1996)

13. Suzuki, T: Generalized distance and existence theorems in complete metric spaces. J. Math. Anal. Appl. 253, 440-458 (2001)

14. Ume, JS: Existence theorems for generalized distance on complete metric space. Fixed Point Theory Appl. 2010 Article ID 397150 (2010)

doi:10.1186/1687-1812-2012-135

Cite this article as: Bin Dehaish and Latif: Fixed point theorems for generalized contractive type multivalued maps. Fixed Point Theory and Applications 2012 2012:135.

\section{Submit your manuscript to a SpringerOpen ${ }^{\odot}$ journal and benefit from:}

- Convenient online submission

- Rigorous peer review

- Immediate publication on acceptance

- Open access: articles freely available online

- High visibility within the field

- Retaining the copyright to your article 